\title{
Barreiras de impermeabilização: configurações aplicadas em aterros sanitários
}

\author{
Waterproofing barriers: settings applied in landfills \\ João Karlos Locastro, Bruno Luiz Domingos De Angelis \\ Universidade Estadual de Maringá
}

\begin{abstract}
Resumo
Com o crescimento das cidades e ampliação na geração de resíduos sólidos urbanos tornam-se cada vez mais comuns à presença de aterros sanitários. Estes aterros devem ser elaborados com barreiras impermeabilizantes (liners) capazes de conter lixiviados, evitando assim espalhamentos de plumas de contaminação. Neste sentido, o presente estudo visa elencar os principais liners encontrados em aterros sanitários, apresentar suas características, além de expor exemplos aplicados em aterros pelo país. Para tanto, foi realizado um levantamento bibliográfico constatando os diferentes liners existentes e suas devidas peculiaridades. Com o estudo observou-se a presença de barreiras impermeabilizantes constituídos por: geossintéticos, lodos, barreiras ativas, resíduos sólidos urbanos, geocomposto bentônico, solo cimento ou solos compactados. Verificou-se ainda que algumas cidades brasileiras, como o caso de Belo Horizonte, utilizam para disposição de resíduos aterros sanitários com a presença de camadas impermeabilizantes alternativas. Como um todo, o liner que apresentou maior segurança entre as classes estudadas foram os liners de geossintéticos combinados a argissolos compactados, apresentando assim menor permeabilidade.
\end{abstract}

Palavras-chave: Liners de aterros sanitários. Contenção de contaminantes. Baixa permeabilidade.

\begin{abstract}
With the growth of cities and expansion in the generation of municipal solid waste are becoming increasingly common the presence of landfills. These landfills must be made with waterproof barriers (liners) able to contain leachate, thereby preventing scattering of contamination plumes. In this sense, this study aims to list the major liners found in landfills, presenting their features, in addition to exposing examples applied in landfills across the country. To this end, it conducted a literature finding the different existing liners and their respective peculiarities. With the study we observed the presence of waterproof barriers consist of: geosynthetics, sludge, active barriers, municipal solid waste, benthic geocomposite, soil cement or compacted soils. It was also found that some Brazilian cities, as the case of Belo Horizonte, use to disposal landfill waste with the presence of alternative waterproofing layers. As a whole, the liner with the highest security among the classes studied were the geosynthetic liners combined with compressed ultisols, thus presenting lower permeability.
\end{abstract}

Keywords: Liners of landfills, Containment of contaminants, Low permeability. 


\section{Introdução}

Em virtude do desenvolvimento industrial, crescimento de áreas urbanas, avanços econômicos e modificação do sistema de consumo, houve uma ampliação demasiada na geração de resíduos por todo o mundo, repercutindo em uma série de problemas de ordem ambiental, econômica e social. Uma das iniciativas adotadas e que vem sendo bem aceita em diversos países são as instalações dos aterros sanitários, sistemas planejados e construídos com o intuito de preservar a segurança local e dispor de forma adequada os resíduos.

Para atender aos critérios de segurança e garantir a eficiência destes sistemas foram criadas ao longo dos anos diversas estruturas que compõem os aterros, denominadas como elementos de proteção.

Dentre os muitos elementos de proteção existentes destacam-se os responsáveis pela impermeabilização do material e contenção de contaminantes dentro dos aterros. Logo, as chamadas barreiras de proteção foram desenvolvidas para atender o objetivo de impermeabilização, sendo estabelecidas ao todo variadas configurações (tipos de liners) seguindo fatores econômicos, grau de periculosidade dos resíduos e riscos ambientais.

Os liners mais usualmente aplicados são os que utilizam como barreiras componentes como: geossintéticos, solos argilosos compactados, resíduos sólidos urbanos, geocomposto bentônico, solo cimento ou uma mistura de diferentes compostos. Ressalta-se ainda que atualmente existam outros liners, porém com estudos em andamento, utilizando, por exemplo, tiras de pneus ou combinação de solos e cal hidratada como forma de barreiras impermeabilizantes.

Neste contexto, o presente trabalho visa elencar os principais liners encontrados atualmente em aterros sanitários, apresentar suas características, além de expor exemplos aplicados em diferentes aterros em todo o país.

\section{Desenvolvimento}

\subsection{Resíduos Sólidos Urbanos}

De acordo com a Norma Brasileira NBR 10.004/87 compreende-se como resíduos sólidos todos os materiais sólidos e semissólidos, provenientes de atividades de origem industrial, doméstica, hospitalar, comercial, agrícola, de serviços e de varrição. Neste grupo são inclusos ainda, lodos provenientes de sistemas de tratamento de água, instalações de controle de poluição, bem como determinados líquidos inviáveis de lançamento na rede pública de esgotos ou corpos de água, ou que exijam para isso soluções técnicas e economicamente inviáveis.

Em virtude do grau de contaminação destes resíduos e dos problemas ambientais associados a sua existência busca-se, cada vez mais, métodos aplicáveis para controle e disposição dos materiais gerados. Historicamente, existem três maneiras básicas utilizadas pela sociedade para dispor e amenizar os problemas dos resíduos, sendo elas: lixões, aterros controlados e aterros sanitários (Charnock \& Wells, 1985).

Atualmente, além das formas de disposição citadas alguns países, principalmente os desenvolvidos, utilizam sistemas modernos de tratamento que antecedem o método de disposição, como exemplo, o processo de incineração, compostagem, tratamento com microondas, plasma pirólise e reciclagem (MUÑOZ, 2002).

Em se tratando das formas básicas de disposição, os aterros sanitários representam o sistema que atua com a melhor forma de controle e disposição dos resíduos. Segundo SILVA (2011) estes sistemas são eficientes porque se atentam a aspectos que interferem no processo, levando em consideração a avaliação de critérios ambientais, de uso e ocupação do solo e operacionais. 
Quanto ao Brasil, o país ainda enfrenta sérios problemas relacionados à ausência de aterros sanitários e aplicação de políticas mais incisivas quanto ao assunto. De acordo com o Instituto Brasileiro de Geografia e Estatística (2008) cerca de 50\% dos municípios no país depositam seus resíduos em lixões, $22,5 \%$ em aterros controlados e apenas $27,5 \%$ possuem aterros sanitários para disposição de resíduos gerados.

A realidade é que o país conta com aparatos de leis muito recentes para questões de disposição dos resíduos, fundamentadas basicamente na Lei no 12.305 da Política Nacional dos Resíduos Sólidos (PNRS) e que ainda apresenta dificuldades financeiras para realmente ser colocada em prática em todo o país.

O maior agravante quanto aos aterros sanitários brasileiros está vinculada a falta de investimentos no setor e o problema de altos custos para implantação e operação dos mesmos. De acordo com a Associação Brasileira de Empresas de Tratamento de Resíduos (2014) os custos da obra são divididos ao longo dos 20 anos de projeto, mas o primeiro ano representa o de maiores receitas, com aproximadamente 6,1\% do montante total. Ressalta-se ainda que estes gastos relativos à implantação estejam vinculados basicamente a dois fatores, sendo eles: aquisição de materiais para a estrutura de aterros e custos relativos à movimentação de terra, necessária para construção das células de resíduos.

A questão da implantação dos aterros acaba sendo algo difícil porque um projeto bem planejado e com um sistema de segurança eficiente demanda uma série de elementos de proteção, inviabilizando a prática do projeto em municípios com carência de recursos.

Os elementos de proteção dos aterros sanitários são definidos como estruturas que compõem os aterros, com o objetivo de permitir a disposição de resíduos sólidos urbanos em locais com exigência de áreas menores e garantia de segurança ao meio ambiente e à saúde pública. De acordo com a Fundação Estadual do Meio Ambiente de Minas Gerais (2005) estes elementos de proteção se encontram distribuídos nos aterros das seguintes formas:

- sistema de cobertura;

- sistema de drenagem superficial;

- sistema de coleta e drenagem de líquidos percolados;

- sistema de tratamento de líquidos percolados;

- sistema de coleta e tratamentos dos gases;

- sistema de impermeabilização de base e laterais;

Cada elemento da composição do aterro tem sua função dentro do sistema e, portanto auxiliam na etapa de operação, evitando danos indesejáveis. Os mecanismos de impermeabilização, por exemplo, atuam na contenção dos contaminantes gerados e diminuem a ocorrência de prejuízos ambientais.

\subsection{Sistemas de impermeabilização}

Consiste no objetivo de confinar os resíduos por meio de barreiras impermeáveis, o que por conseqüência, os protege da entrada de líquidos externos e evita a infiltração de percolados e gases provenientes do aterro no subsolo (BUENO et al., 2004). Segundo Lins et al. (2008) para que estes devidos sistemas funcionem de forma correta e promovam realmente suas funções são necessárias ainda as obtenções de algumas características presentes em materiais de impermeabilização, tais como: estanqueidade; durabilidade; resistência mecânica; resistência a intempéries e compatibilidade físico-químico-biológica com os resíduos a serem aterrados.

De modo geral, um material que reúne todas estas características são as geomembranas de PEAD, que segundo Feldkircher (2008) são amplamente utilizados como impermeabilizantes. Atualmente, verificam-se ainda o uso de outros liners nos aterros, como exemplo, solos impermeabilizantes ou combinação destes com os geossiténticos freqüentemente empregados.

A realidade é que os sistemas impermeabilizantes trabalhados buscam, cada vez mais, atender as necessidades existentes a um menor custo possível e, as variedades de liners cumprem justamente com este objetivo. 


\subsection{Liners utilizados em aterros sanitários}

Os liners estão associados aos sistemas de impermeabilização dos aterros sanitários e são definidas como barreias impermeabilizantes utilizadas para evitar que contaminantes produzidos no aterro se espalhem e atinjam o subsolo e águas subterrâneas. Para Carvalho (1999) os liners consistem em dispositivos empregados quando se deseja reter ao máximo possível os líquidos percolados ou para se evitar a entrada de água no aterro.

Lengen \& Siebken (1996) afirmam que as barreiras de impermeabilização mais antigas utilizavam apenas solos compactados em suas estruturas. Atualmente, os sistemas de impermeabilização evoluíram e passou-se a fazer uso de diversos materiais como exemplo: solo compactado; concreto; emulsões asfálticas; solo-cimento; membranas de bentonita; misturas de areia e bentonita; polietileno clorosulfurado (Hypalon); cloreto polivinílico (PVC); polietileno (PE); polietileno clorado e borracha butílica (BOFF, 1998).

Os sistemas de classificação também evoluíram e os liners passaram a ser classificados em três grupos principais, com a presença de materiais argilosos em sua composição, tais como: liners naturais de argila, liners de argila compactada e liners de argila com geossintéticos (Geosynthetic clay liners - GCL) (DANIEL, 1993). Ainda segundo o autor as barreiras naturais compreendem solos argilosos naturais com baixa condutividade hidráulica, apresentando $\mathrm{k}$ geralmente com variação entre $10^{-6}$ e $10^{-7} \mathrm{~cm} / \mathrm{s}$.

Os liners de argila compactada são constituídos basicamente por solo compactado, mas podem ser combinados com outros materiais como carvão, cinzas, cimento, cal, fibras, bentonita e geossintéticos (KNOP, 2007; REBELO, 2003). Apresentam ainda condutividade hidráulica adequada e são resistentes a influência química do percolado (DANIEL, 1993).

Os liners com geossintéticos são formados por materiais poliméricos com condutividade hidráulica muito baixa e elevadas resistências químicas e físicas. Para Heineck (2002) existem vários tipos de geossintéticos trabalhados comercialmente e tantos outros passíveis de desenvolvimento em campo, com a aplicação de geossintéticos alternados a camadas de argila.

Por fim, deve-se destacar a utilização de liners como forma de cobertura do sistema de aterro. Segundo Knop (2007) estes sistemas servem para confinar o material contaminado do ambiente superficial e controlar o movimento de líquidos e gases. Para Sharma \& Lewis (1994) é um sistema diferente da impermeabilização de fundo, pois necessita de resistência química inferior a exigida por este último, mas requer preocupação quanto a sua durabilidade e exposição, devendo ser resistente a processos erosivos.

Em relação à construção dos liners, não existe uma norma específica ou procedimento a ser seguido no país, mas pode-se recorrer a normas internacionais como o sistema europeu ou americano, desde que adaptados aos solos brasileiros. Independente do sistema construtivo escolhido, o liner a ser executado deve proporcionar qualidade e segurança, garantidos pela baixa permeabilidade e uma espessura mínima da barreira projetada.

Deste modo, deve-se considerar a questão da permeabilidade como uma característica indispensável na determinação do liner, sendo necessária a elaboração de estudos que comprovem a eficiência de aplicação dos diferentes liners. Dentre os muitos estudos desenvolvidos, alguns já demonstram resultados satisfatórios indicados pela utilização de variados compostos, tais como:

\subsubsection{Lodo aplicado como camada de cobertura}

O Lodo proveniente de estações de tratamento de chorume pode ser utilizado como forma de cobertura de aterros após um processo de compactação do material. De acordo com Bizarreta e De Campos (2011) o composto é constituído basicamente por silte e após a secagem de 30 horas apresenta permeabilidade de $1,5 \times 10^{-5} \mathrm{~cm} / \mathrm{s}$.

Os autores ainda afirmam que como cobertura final do aterro sanitário, as propriedades de retenção do material podem sofrer alguma variação pela instabilidade da portlandita quando em contato com o dióxido de carbono.

A vantagem do uso deste sistema é que o lodo não está sujeito a formação de trincas, o que evita a passagem de gás metano pela cobertura e proporciona o melhor aproveitamento do gás. 
2.3.2 Resíduos de construção e demolição (RCD) aplicados como camada de cobertura

Como forma de reaproveitamento e disposição dos resíduos da construção pode-se utilizá-los em cobertura de aterros sanitários, diminuindo o contato direto da massa de lixo com o ambiente externo. De acordo com Catapreta, Simões e Silveira (2011) os RCD's apresentam compactação próxima a 90\%, permeabilidade de $2,3 \times 10^{-3}$ a $5,9 \times 10^{-3} \mathrm{~cm} / \mathrm{s}$, mas valores de umidade dentro do esperado.

O ponto positivo do uso deste liner está vinculado ao custo final da obra. Com os RCD's o custo de impermeabilização diminui, pois geralmente se utiliza materiais do próprio aterro ou resíduos provenientes de obras e construtoras próximas sem nenhum custo adicional.

Os RCD 's podem permitir também a infiltração de uma parcela de águas de chuva. Entretanto, em decorrência de sua alta permeabilidade contribuem para que os lixiviados gerados percolem mais facilmente pelo maciço de resíduos, minimizando a formação de bolsões desses líquidos entre as camadas de resíduos.

\subsubsection{Barreira capilar aplicada como camada de cobertura}

As Barreiras capilares são sistemas de cobertura constituídos por materiais porosos, sendo formada por uma camada de material fino, sobre uma camada de material grosso. Podem ser utilizados como exemplos destes sistemas resíduos sólidos urbanos provenientes do processamento de compostagem (ALMEIDA; IZZO; MAHLER, 2011).

Atua com a finalidade de diminuir a infiltração de água da chuva pelo contraste entre os tamanhos das partículas, permitindo assim, armazenamento da água infiltrada na camada de solo fino, até que possa ser removida por evaporação ou coletada em sistemas de drenagem. Em questão de rendimento, para as condições de estudo os autores verificaram acúmulo de $81,6 \%$ a $93,4 \%$ do volume total de água.

Estes sistemas, assim como os liners de RCD reduzem a utilização de solos de áreas de empréstimo, o que torna o processo de construção da camada de cobertura mais barato e ambientalmente sustentável (ALMEIDA; IZZO; MAHLER, 2011).

2.3.4 Solo compactado aplicado como camada de cobertura e impermeabilização de base

Apesar de apresentar permeabilidade superior aos liners executados com geossintéticos ou combinação destes com solos, os liners elaborados apenas com solos compactados também atuam como impermeabilizantes, exercendo a função de barreiras de proteção.

Uma medida importante a ser adotada na escolha deste liner na configuração do aterro é o diagnóstico prévio do solo, verificando: composição granulométrica, limite de liquidez e plasticidade, além de ensaios de massa específica.

Determinadas as características do solo, pode-se melhorar seu desempenho como barreira elevando a espessura da camada ou aprimorando a compactação do mesmo, reduzindo assim, o número de vazios (ALMEIDA et al., 2010). Este liner apresenta ainda como vantagem a redução de custos, visto que se podem fazer o uso de solos presentes nas proximidades do próprio aterro.

\subsubsection{Geossintéticos aplicados como camada de impermeabilização de base}

O uso de geossintéticos como barreira impermeabilizante cresce a cada ano, principalmente por conseqüência das vantagens adquiridas como: facilidade de construção, durabilidade, controle de qualidade e custo (BUENO et al., 2004).

A técnica evoluiu tanto que atualmente temos a disposição variados produtos comumente aplicados no mercado, sendo eles: geomembranas, geotêxteis, geocompostos argilosos (GCL) e georredes.

As geomembranas, por exemplo, são definidas como mantas poliméricas flexíveis com baixa permeabilidade, algo em torno de $10^{-10} \mathrm{~m} / \mathrm{s}$ (PIMENTAL; PALMEIRA, 2011), sendo fabricadas principalmente de PEAD (polietileno de alta densidade), PVC (polivinil clorado) e PELBD (polietileno linear de baixa densidade) (Bueno ET AL., 2004).

Os geotêxteis protegem a geomembrana evitando que esta seja danificada por puncionamento ou por danos de perfuração por impacto, podendo atuar ainda como filtro em sistemas de drenagem ou de detecção de vazamentos (PIMENTEL; PALMEIRA, 2011). Em relação às georredes os autores 
relatam que as mesmas atuam como mecanismo de drenagem e podem ser utilizadas no sistema de detecção de vazamentos.

Para Rowe (2010) os GCL apresentam permeabilidade de $10^{-11} \mathrm{~m} / \mathrm{s}$ e podem ser uma alternativa à argila compactada oferecendo vantagens técnicas. São constituídos basicamente por uma camada de bentonita confinada entre duas camadas de geotêxtil ou fixada a uma camada de geomembrana.

De forma geral, percebe-se que embora tenhamos diversos geossintéticos, cada um tem sua função dentro do aterro e, portanto, se enquadram as exigências dos clientes. A realidade é que como um todo, este tipo de liner possui segurança satisfatória, pois dispõe de baixa permeabilidade e boa capacidade drenante.

Uma configuração de aterro eficiente e que atribui baixa permeabilidade a barreira são os aterros construídos com combinação destes geossintéticos + solo compactado. $\mathrm{O}$ coeficiente de permeabilidade nestes casos pode chegar a $10^{-12} \mathrm{~m} / \mathrm{s}$, diminuindo a possibilidade de ocorrência de danos ambientais. A fim de se obter sistemas mais restritivos ainda, podem-se utilizar configurações com dupla camada de geomembrana entremeada a solos compactados. Nesta situação, o coeficiente de permeabilidade atinge níveis de cerca de $10^{-14} \mathrm{~m} / \mathrm{s}$.

\subsubsection{Solo cimento aplicado como impermeabilização de base}

Estudos recentes comprovam que a adição de pequenas quantidades de cimento Portland e o incremento do $\mathrm{pH}$ (KNOP, 2007) contribuem na atenuação de contaminantes, reduzindo sua mobilidade e melhorando a capacidade da barreira de controlá-los dentro do aterro, evitando o espalhamento da pluma.

Neste sentido, alguns trabalhos como os desenvolvidos por Korf e Prietto (2011) foram voltado para esta área, a fim de verificar a empregabilidade do composto. Geralmente, é adicionada aos solos argilosos compactados a mistura de $2 \%$ de cimento, sendo este constituído de $5 \%$ de adições minerais e $95 \%$ de clínquer.

Este liner é, sobretudo, o produto resultante da mistura íntima de solo, cimento portland e água que, compactados a um teor ótimo de umidade e sob a máxima densidade, adquirem resistência e durabilidade por meio de reações de hidratação do cimento (ASSOCIAÇÃO ..., 1986).

Apresenta como vantagem boa capacidade para retenção de metais pesados como cádmio e chumbo. Cumpre-se ressaltar ainda que dispõe como ponto negativo a maior ocorrência de reações de precipitação na barreira, o que permite que o contaminante permaneça em solução e possa ser solubilizado na presença de ácido (KORF; PRIETTO, 2011).

\subsubsection{Bentonita aplicada como impermeabilização de base}

A combinação de bentonita + solo local compactado permitem diminuição do coeficiente de condutividade hidráulica, reduzindo, portanto a permeabilidade dos contaminantes presentes no sistema.

De acordo com Lima et al. (2011) as bentonitas são argilo-minerais extremamente higroscópicos, ou seja, apresentam a capacidade de retirar a umidade do meio em que estão com muita facilidade e com isto expandem-se. O mecanismo de expansão funciona basicamente por absorção e adsorção. A absorção permite a entrada de água entre as lamelas da bentonita, onde ocorre o primeiro fenômeno de expansão. No segundo estágio, da adsorção, ocorrem as reações químicas entre a bentonita e a água, causando assim uma nova expansão.

O produto entre o solo argiloso compactado e adição de aproximadamente $4 \%$ de bentonita resulta numa barreira impermeabilizante com coeficiente de permeabilidade de $10^{-7} \mathrm{~cm} / \mathrm{s}$, atendendo a norma 13.896/97 para aterros com resíduos não perigosos.

A utilização deste liner conta a seu favor com a diminuição de custos do empreendimento, além de disponibilidade de solos bentoníticos próximos a aterros em diversos pontos do país, como exemplo, em alguns locais do nordeste. 


\subsection{Exemplos de Liners empregados em aterros sanitários}

\subsubsection{Execução de camada de cobertura final do aterro sanitário de Belo Horizonte}

Os sistemas de cobertura dos aterros devem ser construídos objetivando controlar a entrada de água e ar; minimizar a migração de líquidos lixiviados e biogás para fora do aterro; servir como elemento de redução de odores, vetores de doenças e outros inconvenientes; servir como sistema de controle de águas superficiais e facilitar a recomposição da paisagem (CATAPRETA; SIMÕES; SILVEIRA, 2011).

Neste contexto, para o aterro sanitário de Belo Horizonte optou-se pela implantação de um sistema de multicamadas, constituído pelas seguintes estruturas: camada de resíduos de construção e demolição (camada de regularização), sobreposta com uma camada de argila compactada (barreira hidráulica) e acima desta uma camada de solo vegetal (Figura 1). Entre a camada de fundação e a barreira hidráulica foi implantado um geotêxtil para promover a separação física entre as duas camadas e atuar como elemento auxiliar drenante.

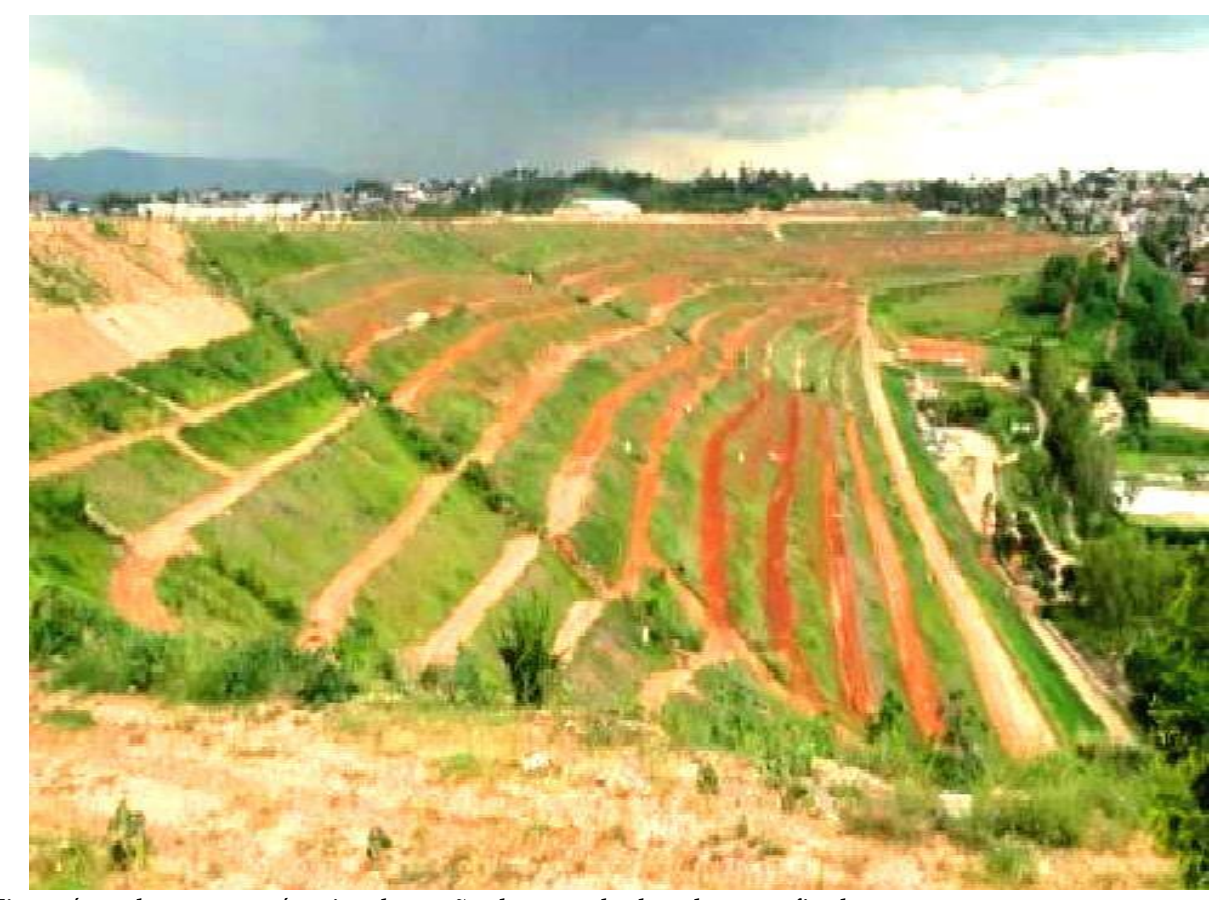

Figura 1 - Vista aérea do aterro após a implantação de camada de cobertura final Fonte: CATAPRETA; SIMÕES; SILVEIRA, 2011

A fim de verificar a eficiência e monitorar as camadas de cobertura instaladas no aterro foram realizados alguns ensaios em laboratório e campo, tais como: granulometria, compactação, permeabilidade, vazões de lixiviado, presença de trincas e formações de erosões.

Pela realização dos ensaios observou-se que os RCD's utilizados na camada de impermeabilização foram resíduos basicamente de classe A constituídos por tijolos, concreto, argamassa, blocos, telhas, placas de revestimentos e solos provenientes de terraplanagem, geralmente passíveis de reciclagem. Os solos utilizados acima da camada de resíduos foram principalmente solos siltosos e argilosos, com fração argilosa mais significativa.

A permeabilidade encontrada no sistema foi inferior as condições recomendada, na qual o coeficiente de permeabilidade deveria variar entre $6,6 \times 10^{-5} \mathrm{~cm} / \mathrm{s}$ a $1,9 \times 10^{-8} \mathrm{~cm} / \mathrm{s}$. Uma hipótese para perda de qualidade em permeabilidade pode está associada à densidade do material que foi de cerca de $9 \mathrm{kN} / \mathrm{m}^{3}$, enquanto que de solos naturais variam entre 14 e $20 \mathrm{kN} / \mathrm{m}^{3}$.

Quanto às precipitações e vazões constatou-se diminuição da vazão de lixiviado após o encerramento do aterro, o que comprova o bom desempenho do liner utilizado. De forma geral, percebeu-se ainda a presença de trincas, mas sem comprometimento na estrutura final do aterro. 
Em decorrência da ação dos sistemas de drenagem, cobertura final e adensamento vegetal não foram identificados neste aterro processos erosivos. Como um todo, notou-se que os resultados sugerem a existência de viabilidade na utilização de RCD como material de cobertura intermediária de RSU, pois apresentaram desempenho adequado sob o ponto de vista sanitário e operacional (CATAPRETA; SIMÕES; SILVEIRA, 2011).

\subsubsection{Sistema de barreiras ativas no aterro sanitário de Campina Grande - PB}

Tendo em vista que o município de Campina Grande na Paraíba não dispõe da presença de um local seguro para tratamento e disposição dos resíduos, sendo os mesmos depositados em um lixão, alguns pesquisadores iniciaram estudos com a finalidade de propor um sistema alternativo para melhorar as condições e elaborar um aterro no local.

Para este município, a idéia principal do sistema de impermeabilização de um novo aterro foi elaborada com o emprego de uma mistura de solo local + solo bentonítico. Verificou-se ainda que o solo bentonítico é uma alternativa recente ainda não explorada em nenhum município do nordeste e , no caso de Campina Grande - PB, apresentou potencial de exploração pela constatação de disponibilidade do material dentro do próprio município (LIMA et al., 2011).

O escopo da pesquisa teve como base a norma NBR 13896/97, seguindo critérios para projeto, implantação e operação em aterros de resíduos não perigosos. Para tanto, recomendou-se respeitar a distância mínima de 1,5 m entre a superfície inferior do aterro e o mais alto nível do lençol freático e considerar como objetivo a obtenção de um coeficiente de permeabilidade inferior a $5 \times 10^{-6} \mathrm{~cm} / \mathrm{s}$, além de uma estrutura capaz de atender as demandas do município (Figura 2).

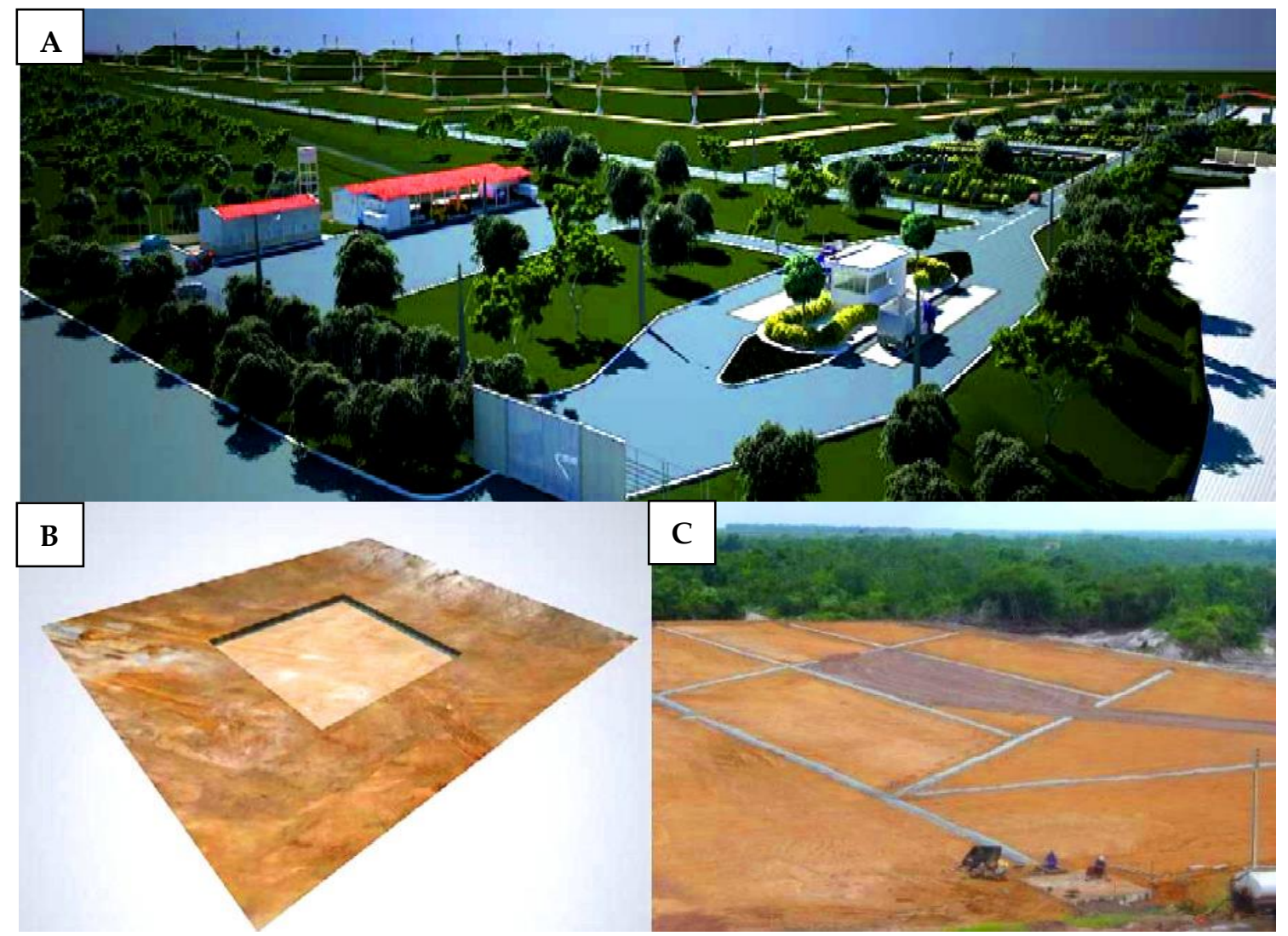

Figura 2 - Esquema de projeto para aterro de Campina Grande - PB. (A) Layot geral do aterro; (B) Sistema de barreira ativa; (C) Implantação da camada impermeabilizante.

Fonte: LIMA et al., 2011.

Por meio de ensaios realizados juntos a Universidade Federal de Pernambuco pôde-se atribuir resultados satisfatórios, chegando à elaboração de uma camada ativa de solo local $(80 \%)+$ solo bentonítico (20\%) com $30 \mathrm{~cm}$ de espessura que atende a norma vigente, com permeabilidade de $10^{-7}$ $\mathrm{cm} / \mathrm{s}$. 
Neste sentido, de acordo com a proposta do estudo o município de Campina Grande - PB passou a dispor de um modelo de aterro sanitário com excelente camada de impermeabilização, permitindo o uso de uma inovação tecnológica com segurança ambiental e geotécnica, possibilitando ainda uma relação custo x benefício de baixo custo e alta eficiência (LIMA et al. 2011).

\section{Conclusões}

Por todo exposto, constatou-se a existência de diversos liners utilizados como barreiras impermeabilizantes, apresentando cada um, diferenças entre si como: custos, coeficiente de permeabilidade e condições de implantação. De todos os liners citados aqueles compostos pela combinação de solo compactado e geossintéticos foram os que apresentaram melhor segurança, garantindo tranqüilidade à população e menores impactos ambientais.

O conhecimento a respeito dos tipos de liners trabalhados atualmente ainda está em total desenvolvimento e novos estudos permeiam a idéia de elaboração de liners mais eficientes, com custos inferiores, resultando em materiais com ampla capacidade de uso e recomendados para novos aterros.

\section{Agradecimentos}

O primeiro autor agradece a Coordenação de Aperfeiçoamento de Pessoal de Nível Superior (CAPES) pela concessão da bolsa de estudo.

\section{Referências}

ALMEIDA, F. T. R.; SANTOS, G. O.; SILVA, R. A. C. da; GOMES, C. C. Caracterização física do solo utilizado em camadas de cobertura no aterro sanitário de Caucaia-Ceará. In: CONGRESSO NORTENORDESTE DE PESQUISA E INOVAÇÃO, 5., Maceió. Anais... Maceió: CONNEPI, 2010.

ALMEIDA, J. R. de; IZZO, R. L. dos S.; MAHLER, C. F. O uso de composto como alternativa de cobertura de aterros. In: CONGRESSO BRASILEIRO DE GEOTECNIA AMBIENTAL, 7., SIMPÓSIO BRASILEIRO DE GEOSSINTÉTICOS, 6., 2011, Belo Horizonte. Anais... Belo Horizonte: REGEO/Geossintéticos, 2011.

ASSOCIAÇÃO BRASILEIRA DE CIMENTO PORTLAND. Dosagem das Misturas de Solo-cimento: Normas de Dosagem e Métodos de Ensaio. São Paulo, SP. ABCP, 57 p. 1986.

ASSOCIAÇÃO BRASILEIRA DE NORMAS TÉCNICAS. NBR 13896/1997: Aterros de Resíduos Não Perigosos - Critérios para Projeto, Implantação e Operação - Rio de Janeiro, 1997.

. NBR 10004/2004: Resíduos Sólidos - Classificação - Rio de Janeiro, 2004.

ASSOCIAÇÃO BRASILEIRA DE TRATAMENTO DE RESÍDUOS. Estudo sobre os Impactos Econômicos e Financeiros da Implantação e Operação de Aterros Sanitários. 2014. Disponível em: < http://www.abetre.org.br/biblioteca/publicacoes/publicacoes-abetre/FGV\%20-

\%20Aterros\%20Sanitarios\%20-\%20Estudo.pdf>. Acesso em: 20 nov. 2014.

BIZARRETA, J. C. O.; DE CAMPOS, T. M. P. Caracterização do lodo de uma estação de tratamento de chorume visando seu emprego em coberturas finais de aterros sanitários. In: CONGRESSO BRASILEIRO DE GEOTECNIA AMBIENTAL, 7., SIMPÓSIO BRASILEIRO DE GEOSSINTÉTICOS, 6., 2011, Belo Horizonte. Anais.. Belo Horizonte: REGEO/Geossintéticos, 2011. 
BOFF, F. E. Estudo da seletividade iônica na interação solo-contaminante aplicado a liners. São Carlos: EESC/USP. Seminário (Seminários Gerais em Geotecnia) - Escola de Engenharia de São Carlos, Universidade de São Paulo, 1998.

BRASIL, 2010. Presidência da República. Lei Federal no 12.305, de 2 de agosto de 2010. Institui a Política Nacional de Resíduos Sólidos; altera a Lei no 9.605, de 12 de fevereiro de 1998; e dá outras providências. Disponível em: <http://www.planalto.gov.br/ccivil_03/_Ato20072010/2010/Lei/L12305.htm >. Acesso em: 19 nov. 2014.

BUENO, B. S.; BENVENUTO, C.; VILAR, O. M. Aplicações em Barreiras Impermeabilizantes: Manual Brasileiro de Geossintéticos. São Paulo: Edgard Blucher, 2004.

CARVALHO, M. F. Comportamento mecânico de resíduos sólidos urbanos. 1999. 300 f. Tese (Doutorado) - Escola de Engenharia de São Carlos, Universidade de São Paulo, São Carlos, 1999.

CATAPRETA, C. A. A.; SIMÕES, G. F.; SILVEIRA, R. M. B. Execução de camada de cobertura final de aterros sanitários de grande porte - estudo de caso do aterro sanitário de Belo Horizonte. In: CONGRESSO BRASILEIRO DE GEOTECNIA AMBIENTAL, 7., SIMPÓSIO BRASILEIRO DE GEOSSINTÉTICOS, 6., 2011, Belo Horizonte. Anais... Belo Horizonte: REGEO/Geossintéticos, 2011.

CHARNOCK, D.; WELLS, C. The challenge of waste disposal. Journal of the Royal Society of Health, v. 105, n. 5, p. 171-178, 1985.

DANIEL, D. E. Geotechnical practice for waste disposal. London: Chapman \& Hall. 1993.

FELDKIRCHER, W. Impermeabilização de aterro sanitário com geomembrana. 2008. $62 \mathrm{f}$. Trabalho de Conclusão de Curso (Bacharel em Engenharia Civil) - Universidade de São Francisco, Itatiba, 2008.

FUNDAÇÃO ESTADUAL DE MEIO AMBIENTE DE MINAS GERAIS. Orientações técnicas para a operação de aterros sanitários. Belo Horizonte: FEAM, 2005.

HEINECK, K. S. Estudo do comportamento hidráulico e mecânico de materiais geotécnicos para barreiras de contenção de resíduos. 2002. 251 f. Programa de Pós-Graduação em Engenharia Civil, Universidade Federal do Rio Grande do Sul, Porto Alegre, 2002.

IBGE - INSTITUTO NACIONAL DE GEOGRAFIA E ESTATÍSTICA. Pesquisa Nacional de Saneamento Básico. 2008. Disponível <http://www.ibge.gov.br>. Acesso em 20 nov. 2014.

KORF, E. P.; PRIETTO, P. D. M. Comportamento hidráulico e reativo de uma mistura compactada solo-cimento como barreira de contenção de resíduos industriais e de mineração. In: CONGRESSO BRASILEIRO DE GEOTECNIA AMBIENTAL, 7., SIMPÓSIO BRASILEIRO DE GEOSSINTÉTICOS, 6., 2011, Belo Horizonte. Anais... Belo Horizonte: REGEO/Geossintéticos, 2011.

LENGEN, A.; SIEBKEN, J. Geomembrane in the United State: A brief discussion. New York: De Groat, Den Hoedt \& Termaat, 1996.

LIMA, J. D. de; CARVALHO JR., F. H. de; JUCÁ, J. F. T.; LIMA, M. T. C. D de. A utilização de um sistema de barreiras ativas em um aterro sanitário no município de Campina Grande - Paraíba Brasil. In: CONGRESSO BRASILEIRO DE ENGENHARIA SANITÁRIA E AMBIENTAL, 26., 2011, Porto Alegre. Anais... Porto Alegre: ABES, 2011. 
LINS, C. M. M.; NÓBREGA, C. C.; LINS, E. A. M.; SILVA, F. M. S.; NOGUEIRA, G. A. B.; JUCÁ, J. F. T.; BELTRÃO, K. G. Q. de B.; ALVES, M. C. M. Resíduos Sólidos: Projeto, operação e monitoramento de aterros sanitários. Salvador: ReCESA, 2008.

KNOP, A. Estudo do comportamento de liners atacados por ácido sulfúrico. 2007. 256 f. Tese (Doutorado em Engenharia) - Programa de Pós-Graduação em Engenharia Civil, Universidade Federal do Rio Grande do Sul, Porto Alegre, 2007.

MUÑOZ, S. I. S. Impacto ambiental na área do aterro sanitário e incinerador de resíduos sólidos de Ribeirão Preto, SP: Avaliação dos níveis de metais pesados. 2002. 158 f. Tese (Doutorado em Enfermagem) - Escola de Enfermagem de Ribeirão Preto, Universidade de São Paulo, Ribeirão Preto, 2002.

PIMENTEL, K. C. A.; PALMEIRA, E. M. Reabilitação de barreiras impermeabilizantes com geossintéticos. In: CONGRESSO BRASILEIRO DE GEOTECNIA AMBIENTAL, 7., SIMPÓSIO BRASILEIRO DE GEOSSINTÉTICOS, 6., 2011, Belo Horizonte. Anais... Belo Horizonte: REGEO/Geossintéticos, 2011.

REBELO, K. M. W. Resistência de interface entre geomembranas e solos através do ensaio de Ring Shear. 2003. 216 f. Dissertação (Mestrado em Geotecnia) - Escola de Engenharia de São Carlos, Universidade de São Paulo, São Carlos, 2003.

RIBEIRO, R. A. V. Avaliação do desempenho hidráulico de barreiras de proteção ambiental produzidas com solo laterítico arenoso compactado, estabilizado quimicamente. 2002. $81 \mathrm{f}$. Dissertação (Mestrado em Engenharia Civil) - Faculdade de Engenharia, Universidade Estadual Paulista Júlio de Mesquita Filho, Ilha Solteira, 2002.

ROWE, K. Role of GCL's in Controlling Leakage through Composite Liners, Proceedings. In: INTERNATIONAL SYMPOSIUM ON GEOSYNTHETIC CLAY LINERS, 3., Wurzburg. Anais... Wurzburg: ConSem GmbH, 2010.

SHARMA, H. D.; LEWIS, S. P. Waste containment systems, waste stabilization and landfills: design e evaluation. New York: J. Wiley. 1994.

SILVA, N. L. da S. e. Aterro sanitário para resíduos sólidos urbanos - RSU - matriz para seleção da área de implantação. 2011. 68 f. Trabalho de Conclusão de Curso (Bacharel em Engenharia Civil) Departamento de Tecnologia, Universidade Federal de Feira de Santana, Feira de Santana, 2011. 